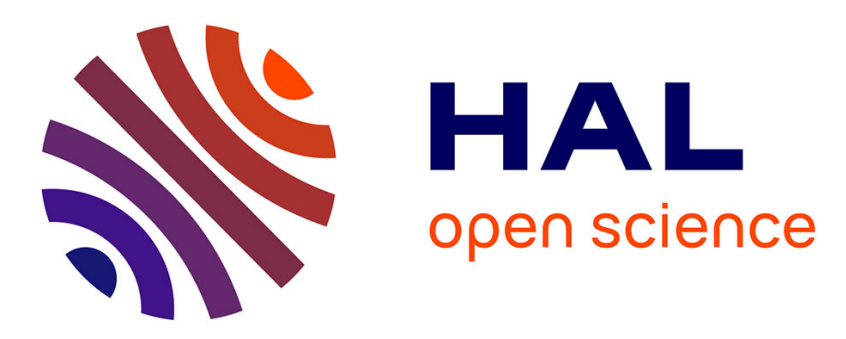

\title{
Dearomatization of 3-cyanoindoles by $(3+2)$ cycloaddition: from batch to flow chemistry
}

Maxime Manneveau, Saori Tanii, Fanny Gens, Julien Legros, Isabelle Chataigner

\section{- To cite this version:}

Maxime Manneveau, Saori Tanii, Fanny Gens, Julien Legros, Isabelle Chataigner. Dearomatization of 3-cyanoindoles by $(3+2)$ cycloaddition: from batch to flow chemistry. Organic \& Biomolecular Chemistry, 2020, 18 (18), pp.3481-3486. 10.1039/d0ob00582g · hal-02996918

\section{HAL Id: hal-02996918 https://hal.science/hal-02996918}

Submitted on 11 Nov 2020

HAL is a multi-disciplinary open access archive for the deposit and dissemination of scientific research documents, whether they are published or not. The documents may come from teaching and research institutions in France or abroad, or from public or private research centers.
L'archive ouverte pluridisciplinaire HAL, est destinée au dépôt et à la diffusion de documents scientifiques de niveau recherche, publiés ou non, émanant des établissements d'enseignement et de recherche français ou étrangers, des laboratoires publics ou privés. 


\section{Dearomatization of 3-Cyanoindoles by $(3+2)$ Cycloaddition: From Batch to Flow Chemistry}

Received 00th January 20xx, Accepted 00th January $20 x x$

DOI: 10.1039/x0xx00000x

1,3-Dipolar dearomatizing cycloadditions between a nonstabilized azomethine ylide and 3-cyanoindoles or benzofuran afford the corresponding 3D-heterocycles bearing a quaternary carbon centre at the ring junction. While 6 equivalents of ylide precursor 1 are required for full conversion in a classical flask, working under flow conditions limits the excess ( 3 equiv., $t^{R}=1$ min) and leads to a cleaner process, affording cycloadducts that are easier to isolate.

Dearomative processes have turned into a hot topic for their ability to metamorphose trivial aromatic compounds into valuable functionalized polycyclic compounds in one single operation. ${ }^{1}$ Different types of cycloadditions have shown their efficiency in dearomatizing electron-poor arenes, in concerted or stepwise reactions. This includes $(2+1),{ }^{2}(4+2),{ }^{3}(3+2)^{4}$ or combined $(4+2) /(3+2)$ cycloadditions. ${ }^{5}$ In most of the cases considered, the aromatic ring is substituted by a nitro group owing to its high electron-withdrawing power. Hence, nitroarenes, in particular 3-nitroindoles, have been recently efficiently reacted with different 1,3-dipoles in $(3+2)$ (formal) cycloadditions, $^{4 \mathrm{~b}, 6}$ or with electron-rich 1,3-dienes, enolates or enamines in $(4+2)$ (formal) cycloaddition processes among other processes. $^{3 b, 7}$ The situation becomes more complex when the nitro substituent on the aromatic ring is replaced by a cyano group, a motive much less attracting and possibly sensitive to the reaction conditions. The Mayr scale indeed shows a huge difference between the electrophilicities of nitrostyrene $\left(\mathrm{E}\left(\mathrm{Ph}-\mathrm{C}=\mathrm{C}-\mathrm{NO}_{2}\right)=-13.85\right)$ and cinnamonitrile $(\mathrm{E}(\mathrm{Ph}-\mathrm{C}=\mathrm{C}-\mathrm{CN})=-24.60)$ for instance. ${ }^{8}$ This dissimilarity translates into a different reactivity toward nucleophiles and we have shown that cycloadditions between electron-poor benzonitriles and a non-stabilized azomethine ylide derails the dearomatization process observed with nitrobenzenes, since

\footnotetext{
Normandie Université, UNIROUEN, CNRS, INSA Rouen, COBRA laboratory, F-76000 Rouen, France

E-mail: julien.legros@univ-rouen.fr; isabelle.chataigner@univ-rouen.fr.

${ }^{b}$. Department of Organic Chemistry, Graduate School of Pharmaceutical Sciences,

Tohoku University, Aoba, Sendai, 980-8578, Japan.

c. Present address: CNRS, Sorbonne Université, LCT UMR 7616, F-75005 Paris, France.

Electronic Supplementary Information (ESI) available: [details of any supplementary information available should be included here]. See
} DOI: $10.1039 / \times 0 \times x 00000 x$ another $(3+2)$ reaction takes place between the $\mathrm{C} \equiv \mathrm{N}$ and the dipole in this case (Scheme 1). ${ }^{9}$ With the less aromatic indole ring, we show herein that 3 -cyanoindoles behave again as $\mathrm{C}=\mathrm{C}$ dipolarophiles ${ }^{10}$ and undergo fast dearomatization through 1,3-dipolar cycloaddition to afford original 3D-scaffolds within a single minute reaction time (Scheme 1 ).

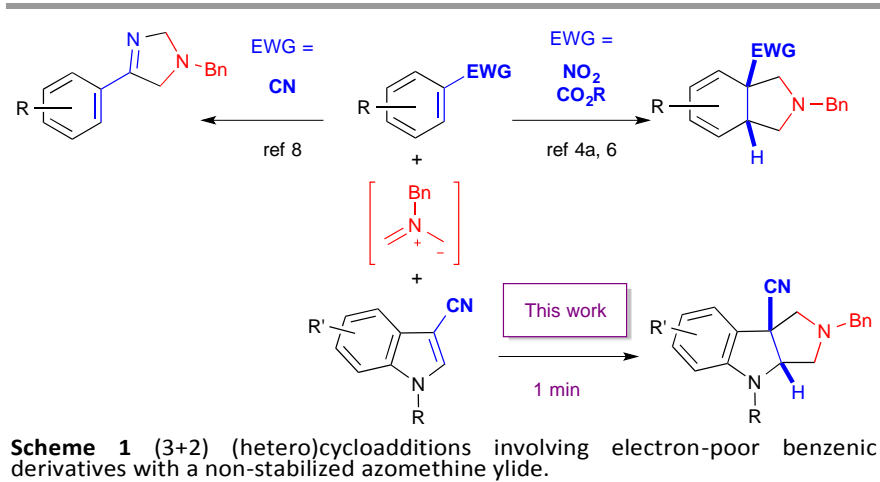

Our previous works prompted us to launch this study on cyanoindole $\mathbf{2 a}$, bearing an activating/protecting tosyl group on the nitrogen atom. Reacting $2 \mathrm{a}$ with a large 9 equiv excess of hemiaminal $\mathbf{1}$ and a catalytic amount of trifluoroacetic acid (TFA), added over $30 \mathrm{~min}$ at $0{ }^{\circ} \mathrm{C}$, resulted in the conversion of most of the starting material (84\%) and formation of a single adduct (Table 1 , entry 1 ). The dearomatized indoline $\mathbf{3 a}$ was isolated in $58 \%$ yield. ${ }^{11}$ In order to enhance the conversion, we explored the influence of the nitrogen protecting group, as this was shown to have a great impact on the reactivity in cycloadditions of indolic derivatives. ${ }^{12}$ In particular, carbonyl based protecting groups (amide, carbamate) were found to be more reactive than their sulfonyl based counterparts, in some cases. However, the benzoylated indole $\mathbf{2 c}$ did not lead to the desired cycloadduct (entry 2 ) while carbamate $\mathbf{2 d}$ furnished $\mathbf{3 d}$ in a lower yield under the same conditions (entry 3 ). We thus turned our attention toward the trifluoromethylsulfonyl (Tf) group having a stronger electron-withdrawing inductive effect. The $\mathbf{N}$-Tf-indole $\mathbf{2} \mathbf{d}$ was found to fulfil the desired criteria of the reaction, leading to a full conversion of the starting material and affording the dearomatized cycloadduct $\mathbf{3 d}$ in an increased $78 \%$ yield (entry 4). Further optimization of the reaction was achieved by studying the influence of the 
reaction time and of the hemiaminal excess. The best result was observed in the presence of a 6 -fold excess of 1 (entry 5). With 4 equiv. of 1 only $73 \%$ conversion was observed (entry 6 ). With 6 equiv, the reaction time could even be reduced (entries 7 and 8) and we noticed that the conversion was nearly complete just after the end of the catalyst dropwise addition (30 minutes), furnishing the cycloadduct in a similar $88 \%$ isolated yield (entry 8).

Table 1.Optimization of reaction conditions. ${ }^{\text {[a] }}$

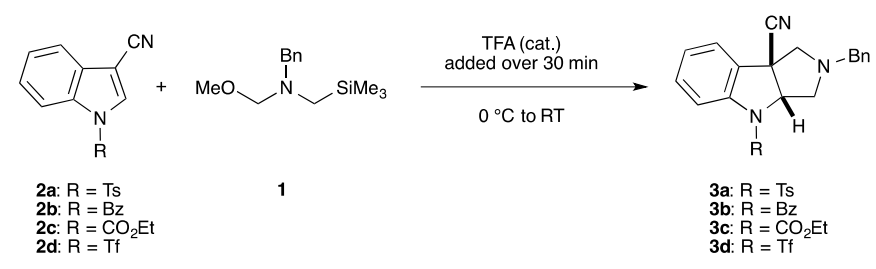

\begin{tabular}{ccccc}
\hline Entry & $\mathrm{R}$ & Time $^{[\mathrm{b}]}(\mathrm{h})$ & $\begin{array}{c}\text { Equiv. of } \\
\mathbf{1}\end{array}$ & $\begin{array}{c}\text { Conv. (\%) } \\
\left.\left(\text { Yield }^{[\mathrm{c}]}\right)\right)^{[\mathrm{d}]}\end{array}$ \\
\hline 1 & $\mathrm{Ts}$ & 18 & 9 & $84(58)$ \\
2 & $\mathrm{Bz}$ & 18 & 9 & $100(0)^{[\mathrm{e}]}$ \\
3 & $\mathrm{CO}_{2} \mathrm{Et}$ & 18 & 9 & $70(41)$ \\
4 & $\mathrm{Tf}$ & 18 & 9 & $100(78)$ \\
5 & $\mathrm{Tf}$ & 24 & 6 & 100 \\
6 & $\mathrm{Tf}$ & 24 & 4 & 73 \\
7 & $\mathrm{Tf}$ & 2 & 6 & $100(80)$ \\
8 & Tf & 0 & 6 & $97(88)$
\end{tabular}

${ }^{\text {a }}$ Reactions were carried out in DCM ( $\left.0.25 \mathrm{M}\right)$ with 1 equiv of $\mathbf{2}$ and 4 to 9 equiv of 1. The TFA catalyst ( $7 \mathrm{~mol} \%$ in relation to $1,0.18 \mathrm{M}$ solution in DCM) was added dropwise at $0^{\circ} \mathrm{C}$ over $30 \mathrm{~min}$. The mixture was warmed up and stirred at r.t. for the requisite time. ${ }^{\mathrm{b}}$ Reaction time after the end of the dropwise TFA addition; ${ }^{\mathrm{c}}$ conversion of $\mathbf{2}$, determined by ${ }^{1} \mathrm{H}$ NMR on the crude mixture (considering the indole/indoline $\mathrm{H} 2$ shifting, from 7.92 to $5.15 \mathrm{ppm}$ on the triflated compounds for

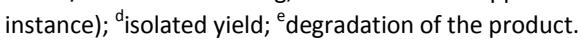

This last observation was supported by in-line infrared analysis of the reaction mixture. $\mathbf{2 d}$ is characterized by absorption bands at $1429 \mathrm{~cm}^{-1}$ and $977 \mathrm{~cm}^{-1}$, probably corresponding to the reactive olefinic $C^{2}=C^{3}$ double bond. On the other hand, 1 features signals at $1067 \mathrm{~cm}^{-1}$ and $1249 \mathrm{~cm}^{-1}$ possibly corresponding to the $\mathrm{CH}_{3}-\mathrm{O}-\mathrm{CH}_{2}$ and $\mathrm{Si}-\mathrm{CH}_{3}$ fragments. These latters disappear while adding TFA to the reaction mixture. Alongside, bands at $1406 \mathrm{~cm}^{-1}$ and $1200 \mathrm{~cm}^{-1}$, illustrating the formation of cycloadduct 3d, appear once the TFA is added dropwise. The intensity of these signals is almost at its maximum at the end of the TFA addition, suggesting that the desired product $\mathbf{3 d}$ was nearly entirely formed.

The reaction was extended to other 3-cyanoindole derivatives (Scheme 2). ${ }^{13}$ We first turned our attention to cyanoindoles bearing a bromine atom on the aromatic 6membered ring. Thus the 5- and 6-bromoindole derivatives nicely furnished the corresponding dearomatized indolines $3 \mathrm{e}$ and $\mathbf{3 f}$ in 92 and $79 \%$ yield, respectively, within $2 \mathrm{~h} .{ }^{14}$ Addition of an electron-withdrawing group on positions 4 or 5 of the aromatic ring had no undesirable effect on the reaction yields and the desired product $\mathbf{3 g}$ and $\mathbf{3 h}$ were isolated in $93 \%$ and $73 \%$ yield, respectively. No competition of other aromatic or $\mathrm{C} \equiv \mathrm{N}$ bonds was observed. Different 3-cyanoindoles bearing an extra aromatic substituent in position 5 were also welltolerated, furnishing the aryl substituted cycloadducts $\mathbf{3 i - 3 p}$ in good yields. The aromatic can be a simple phenyl group (3i), a phenyl bearing an electron-withdrawing (3j-3k) or an electrondonating group (3l-3m), an electron-rich heteroaromatic (3n3o) or an electron-poor pyridine (3p), showing the broad diversity of the possible aromatic substitution. The indole derivative bearing a silylalkynyl group in position 5 could also be used in this reaction, leading to the exclusive formation of $3 q$, isolated in $92 \%$ yield. No competitive cycloaddition involving the triple bond was observed in this case, as expected with the electron-rich azomethine ylide dipole engaged in the reaction. The 3-cyano-2-methyl-Ntrifluoromethylsulfonylindole however proved inert in this process, as anticipated for an aromatic tetrasusbstituted dipolarophile. Note that different aromatic substrates can also react efficiently, as demonstrated with 3-cyanobenzofuran furnishing the dearomatized tetrahydrobenzofuropyrrole $\mathbf{3 r}$ in a good $90 \%$ yield.

Despite, the large scope of substrates that can be used under these conditions, the use of a large excess of the ylide precursor (6 equiv) remains a drawback. This dipole is generated by the slow addition of TFA on a mixture of hemiaminal and dipolarophile in dichloromethane. The slow addition intends to avoid the competitive self-condensation of the reactive dipole. However, the TFA concentration increases along the addition, which may speed up the ylide consumption in the competitive process. In this perspective, miniaturized reactors in continuous flow have been shown to be a remarkable tool for organic synthesis. ${ }^{15}$ Due to excellent heat and mass transfer, as well as-This is notably due to precise control of reaction time in flow microreactors (residence time $t^{R}$ ), allowing highly reactive compounds to be formed and trapped before further adverse transformation can occur. ${ }^{15 b, 16}$ Whereas a slow addition of a reagent cannot be achieved in an integrated flow set-up, it is worth to note that each point of a simple tubular reactor describes a specific state of the reaction progress without accumulation of reagents, by contrast with the previous discontinuous batch reactor. Hence, Ley reported the flow synthesis of 3-nitropyrrolidines from an in situ generated ylide and nitroalkenes as dipolarophiles $\left(t^{R}=30-90\right.$ min at $\left.60-120{ }^{\circ} \mathrm{C}\right) .{ }^{17}$ In this context, we decided to transpose our dearomative $(3+2)$ cycloaddition of cyanoindoles from batch to flow conditions and implemented the new process described on Scheme 3. 
<smiles>N#CC12CN(Br)C[C@@H]1N([Tl])c1ccc(Br)cc12</smiles>

3e

Batch: $92 \%$

Flow: $86 \%$

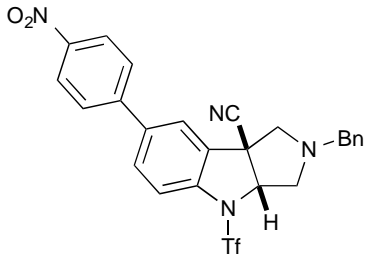

3j

Batch: $95 \%$

Flow: $86 \%$<smiles>N#CC12CN(Cc3ccccc3)C[C@H]1N([Tl])c1cc(Br)ccc12</smiles>

$3 f$

Batch: $79 \%$

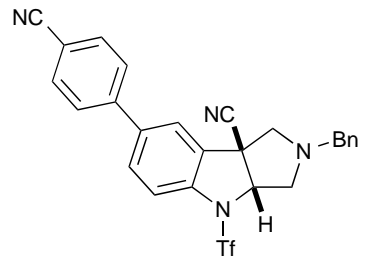

$3 k$

Batch: $94 \%$

Flow: 92\%<smiles>CCCC1(C)CN(Br)C[C@H]1N1c2cccc(C(=O)O)c2C1(C)C</smiles>

$3 \mathrm{~g}$

Batch: $93 \%$

Flow: $88 \%$<smiles>N#CC12CN(Br)CC1N([Al])c1ccc([N+](=O)[O-])cc12</smiles>

3h

Batch: $73 \%$

Flow: $75 \%$

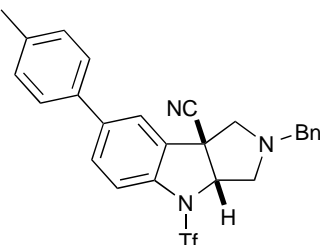

31

Batch: $91 \%$

Flow: $86 \%$

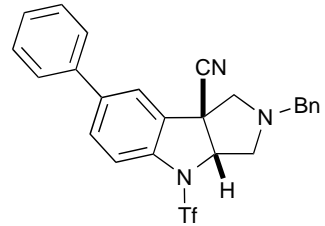

3i

Batch: $97 \%$ Flow: $97 \%$<smiles>CC1(C)CN(Cc2ccccc2)CC1Nc1ccccc1</smiles>

3n

Batch: $95 \%$

Flow: $86 \%$

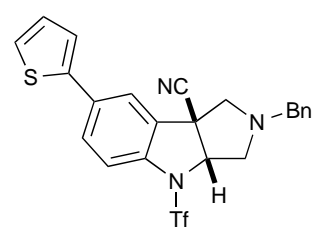

30

Batch: $95 \%$

Flow: $86 \%$

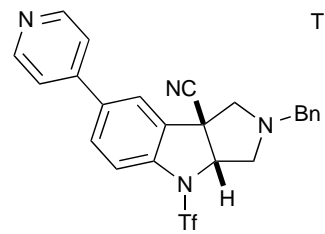

$3 p$

Batch: $97 \%$ Flow: 93\%

TMS

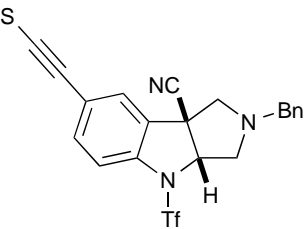

$3 q$

Batch: $92 \%$

Flow: $91 \%$

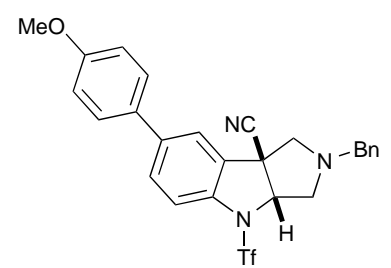

$3 m$

Batch: $93 \%$

Flow: $81 \%$

Scheme 2 Scope of the $(3+2)$ dearomatizing cycloaddition. Comparison of batch ( 6 equiv of $1,0.72$ eq of TFA over 30 min then $2 \mathrm{~h}, 0{ }^{\circ} \mathrm{C}$ to RT) and flow ( 3 eq of $1,0.24$ eq of TFA, $1 \mathrm{~min}, 36^{\circ} \mathrm{C}$ ) conditions.

The system was composed of two inlets, inlet 1 containing TFA and inlet 2 containing a mixture of hemiaminal $\mathbf{1}$ and cyanonidole $\mathbf{2} \mathbf{d}$ (set-up A). The influence of several parameters was investigated (Table 2).

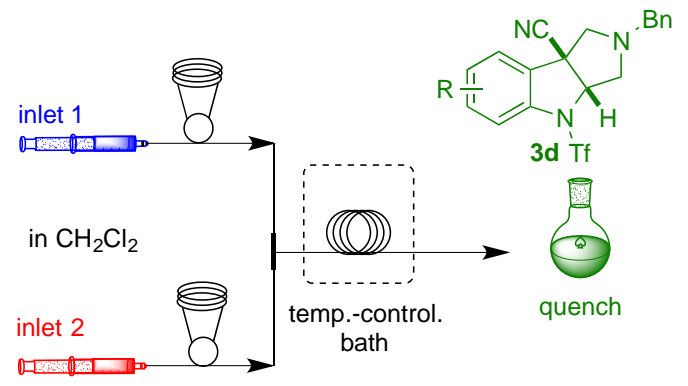

Set-up A

TFA

Hemiaminal 1, Cyanoindole 20
Set-up B

TFA, Cyanoindole 2d Hemiaminal 1
Scheme 3 Flow set-up for the $(3+2)$ dearomatization of cyanoindoles.

\begin{tabular}{cccccccc}
\hline \multicolumn{2}{c}{ Table 2 } & Optimization of reaction conditions between $\mathbf{1}$ and $\mathbf{2 d}$ in flow process. ${ }^{[\mathrm{a}]}$ \\
\hline Entry & $\begin{array}{c}\text { Flow } \\
\text { rate }^{[\mathrm{b}]} \\
(\mathrm{mL} / \mathrm{min})\end{array}$ & $\begin{array}{c}\text { Reactor } \\
\text { volume } \\
(\mathrm{mL})\end{array}$ & $\begin{array}{c}t^{R} \\
(\mathrm{~min})\end{array}$ & $\begin{array}{c}\text { Equi } \\
\text { v of } \\
\mathbf{1}\end{array}$ & $\mathrm{T}^{\circ} \mathrm{C}$ & $\begin{array}{c}{[\mathrm{TFA}]} \\
(\mathrm{M})\end{array}$ & $\begin{array}{c}\text { Conv } \\
(\%)\end{array}$ \\
\hline 1 & 2 & 10 & 5 & 6 & 20 & 0.18 & 97 \\
2 & 10 & 10 & 1 & 6 & 20 & 0.18 & 98 \\
3 & 20 & 10 & 0.5 & 6 & 20 & 0.18 & 100 \\
4 & 20 & 10 & 0.5 & 4 & 20 & 0.18 & 73 \\
5 & 20 & 10 & 0.5 & 2 & 20 & 0.18 & 40 \\
6 & 20 & 10 & 0.5 & 4 & 20 & 0.12 & 95 \\
7 & 20 & 10 & 0.5 & 4 & 20 & 0.08 & 75 \\
8 & 20 & 20 & 1 & 4 & 50 & 0.08 & 100 \\
9 & 20 & 20 & 1 & 4 & 36 & 0.06 & 100 \\
$\mathbf{1 0}$ & $\mathbf{2 0}$ & $\mathbf{2 0}$ & $\mathbf{1}$ & $\mathbf{3}$ & $\mathbf{3 6}$ & $\mathbf{0 . 0 6}$ & $\mathbf{1 0 0}$ \\
11 & 20 & 20 & 1 & $\mathbf{2}$ & 36 & 0.06 & 40
\end{tabular}

${ }^{[a]}$ Reaction conditions: DCM $(0.25 \mathrm{M})$, quench: $\mathrm{Et}_{3} \mathrm{~N}(1.5 \mathrm{mmol}) .{ }^{[\mathrm{b}]}$ Total flow rate.

First experiments were assessed with a $10 \mathrm{~mL}$-microreactor tube, immersed in a $20^{\circ} \mathrm{C}$ bath, with 6 equivalents of 1 and [TFA] $=0.18 \mathrm{M}$ (0.72 equiv), at a total flow rate of $2 \mathrm{~mL} / \mathrm{min}$ (entry 1 ). The result was encouraging since $97 \%$ conversion into $\mathbf{3 d}$ was attained within only 5 min reaction. Whereas it is often claimed that microflow systems provide enhanced mixing, the T-shaped mixers and reactor sizing imposes a 
formal laminar regime. With such features mixing is actually increased according to some adjustments: high flow rates in the reactor ( $>10 \mathrm{~mL} / \mathrm{min}$ ) and close media for each inlet (both in $\mathrm{CH}_{2} \mathrm{Cl}_{2}$ here). Increasing the flow rate to 10 then $20 \mathrm{~mL} / \mathrm{min}$ reduced the residence time to $1 \mathrm{~min}$ and $30 \mathrm{~s}$ respectively (entries 2 and 3). Delightfully, at both these $t^{R}$, a nearly complete conversion of the substrate into cycloadduct was observed.

It was then assessed if the quantity of $\mathbf{1}$ could be reduced. Unfortunately, conversion dropped significantly (entries 4 and 5). It was next noticed that the TFA loading was essential and that decreasing its quantity increased the conversion of the substrate (entry 6). Parameters were then tuned in order to get the highest yield at the shortest $t^{R}$ with the lowest quantity of TFA and ylide precursor 1 (entries 7-11). An optimum result was found at a flow rate of $20 \mathrm{~mL} / \mathrm{min}$ in a $20 \mathrm{~mL}$-reactor heated at $36^{\circ} \mathrm{C}\left(t^{R}=1 \mathrm{~min}\right)$ with 3 equiv of 1 and 0.24 equiv of TFA ( $C=0.06 \mathrm{M}$; entry 10$)$. For comparison, a reaction run in 1 minute (TFA addition) in classical batch conditions led to $44 \%$ conversion into $\mathbf{3 d}$, confirming the positive effect of the flow conditions on this transformation.

The scope of the reaction was then evaluated with the same flow set-up and compared to batch conditions (Scheme 2 ). Results were in line with the first experiment and all the twelve substrates involved gave excellent yields (75-97\%) within only 1 min and 3 equiv of 1 . It is worth noting that the setup had to be adapted for the substrate $\mathbf{2} \mathbf{j}$ which was insoluble in $\mathrm{CH}_{2} \mathrm{Cl}_{2}$. However when adding the proper amount of TFA in the same syringe (inlet 1 ), the solution turned homogeneous and the syringe pumps could be triggered to start the reaction which took place nicely (set-up B).

The heterocyclic dearomatized compounds resulting from this transformation represent interesting scaffolds that could easily undergo further functionalization in an effort to further increase their molecular diversity (Scheme 4). For instance, 3e reacted nicely under classical Suzuki coupling conditions to furnish the expected product $4 \mathbf{e}$. The cyano group could then be reduced into the corresponding amine by $\mathrm{LiAlH}_{4}$. Simultaneously, this led to the deprotection of the triflyl group, affording $\mathbf{5 e}$ in $95 \%$ yield. Noteworthy, $\mathbf{5 e}$ bears three differently substituted amino functional groups. These transformations illustrate the vast potential of these dearomatized cycloadducts, that can easily be derivatized into differently substituted polyamino-indolines, structures of interest as bioactive molecules, organocatalysts or coordinating ligands for instance. ${ }^{18}$ Efforts directed toward further derivatizations of these tricyclic indolines are currently under way.

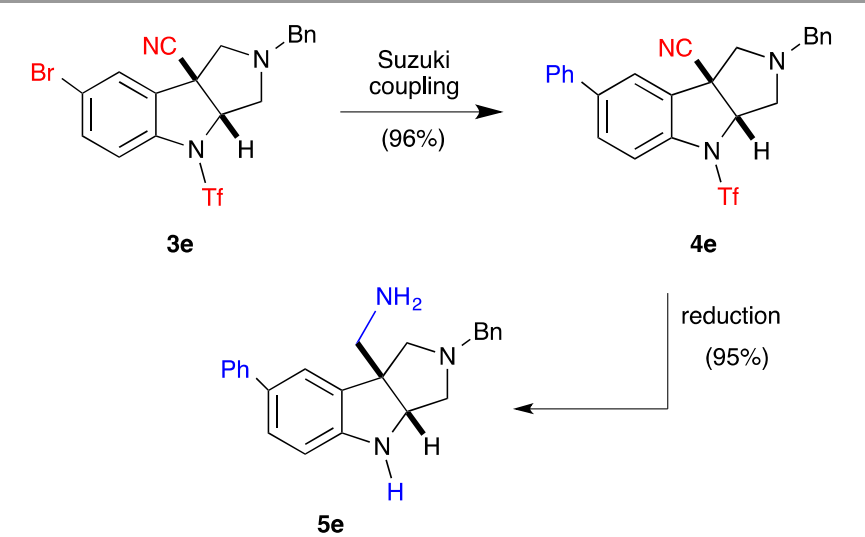

Scheme 4 Further functionalizations of product 3e. Suzuki coupling: $\mathrm{PhB}(\mathrm{OH})_{2}$ XPhos-Pd-G2 (1.5 mol\%), $\mathrm{K}_{3} \mathrm{PO}_{4}$, dioxane $/ \mathrm{H}_{2} \mathrm{O}, \Delta$; Reduction: $\mathrm{LiAlH}_{4}, \mathrm{THF}$, reflux.

In short, we have shown that 3-cyanoindoles behave as $\mathrm{C}=\mathrm{C}$ dipolarophiles when reacted with an electron-rich azomethine ylide 1,3-dipole. The dearomatization of these heterocycles takes place smoothly, in the absence of any metal catalyst. The $(3+2)$ cycloaddition affords novel and highly functionalized tricyclic indolines bearing a quaternary centre at the ring junction, from easily available substrates. This reaction is very simple to set up and allows an efficient dearomatization process to take place under classical batch conditions using a 6 -fold excess of reagent, in 30 to 150 minutes. When transposed to flow conditions, the reaction rate is accelerated to only $1 \mathrm{~min}$, with a lesser excess of reagents. These results pave the way to fast dearomatizing processes for the access to a large family of structurally sophisticated 3D molecules in a very simple way.

\section{Conflicts of interest}

There are no conflicts to declare.

\section{Acknowledgements}

The authors gratefully acknowledge the European France(Manche)-England cross-border cooperation program INTERREG IV A "AI-CHEM CHANNEL" and INTERREG V A "LABFACT", co-financed by ERDF, and the Tohoku University Center for Gender Equality Promotion (TUMUG) for financial support. Labex SynOrg (ANR-11-LABX-0029), Rouen University, CNRS and INSA Rouen are kindly thanked for financial support.

\section{Notes and references}

1 For reviews, see for instance: (a) F. López Ortiz, M. J. Iglesias, I. Fernández, C. M. Andújar Sánchez and G. Ruiz Gómez, Chem. Rev., 2007, 107, 1580-1691. (b) S. P. Roche and J. A. Porco, Angew. Chem. Int. Ed., 2011, 50, 4068-4093. (c) E. Manoni, A. De Nisi and M. Bandini, Pure Appl. Chem., 2016, 88, 207-214. (d) J. Preindl, S. Chakrabarty and J. Waser, Chem. Sci., 2017, 8, 
7112-7118. (e) G. Huang and B. Yin, Adv. Synth. Catal., 2019, 361, 405-425.

2 D. Antoniak and M. Barbasiewicz, Org. Lett., 2019, 21, 93209325.

3 See for instance: (a) E. Wenkert, P. D. R. Moeller and S. R. Piettre, J. Am. Chem. Soc., 1988, 110, 7188-7194. (b) B. Biolatto, M. Kneeteman, E. Paredes and P. M. E. Mancini, J. Org. Chem., 2001, 66, 3906-3912. (c) I. Chataigner, E. Hess, L. Toupet and S. R. Piettre, Org. Lett., 2001, 3, 515-518. (d) A. Chrétien, I. Chataigner and S. R. Piettre, Chem Commun, 2005, 1351-1353. (e) J. Boonsombat, H. Zhang, M. J. Chughtai, J. Hartung and A. Padwa, J. Org. Chem., 2008, 73, 3539-3550. (f) N. Chopin, H. Gérard, I. Chataigner and S. R. Piettre, J. Org. Chem., 2009, 74, 1237-1246. (g) S. Lakhdar, F. Terrier, D. Vichard, G. Berionni, N. El Guesmi, R. Goumont and T. Boubaker, Chem. - Eur. J., 2010, 16, 5681-5690. (h) A. S. Kil'met'ev, E. E. Shul'ts, M. M. Shakirov, T. V. Rybalova and G. A. Tolstikov, Russ. J. Org. Chem., 2013, 49, 872-885.

4 See for instance: (a) S. Lee, I. Chataigner and S. R. Piettre, Angew. Chem. Int. Ed., 2011, 50, 472-476. (b) B. M. Trost, V. Ehmke, B. M. O'Keefe and D. A. Bringley, J. Am. Chem. Soc., 2014, 136, 8213-8216.

5 See for instance: (a) D. Giomi, S. Turchi, A. Danesi and C. Faggi, Tetrahedron, 2001, 57, 4237-4242. (b) I. Chataigner and S. R. Piettre, Org. Lett., 2007, 9, 4159-4162. c) H. Gérard and I. Chataigner, J. Org. Chem., 2013, 78, 9233-9242.

6 See for instance : (a) S. Roy, T. L. S. Kishbaugh, J. P. Jasinski and G. W. Gribble, Tetrahedron Lett., 2007, 48, 1313-1316. (b) S Lee, S. Diab, P. Queval, M. Sebban, I. Chataigner and S. R. Piettre, Chem. - Eur. J., 2013, 19, 7181-7192. (c) A. Awata and T. Arai, Angew. Chem. Int. Ed., 2014, 53, 10462-10465. (d) A. L. Gerten and L. M. Stanley, Org. Chem. Front., 2016, 3, 339-343. (e) M. Laugeois, J. Ling, C. Férard, V. Michelet, V. Ratovelomanana-Vidal and M. R. Vitale, Org. Lett., 2017, 19, 2266-2269. (f) H. Wang, J. Zhang, Y. Tu and J. Zhang, Angew. Chem. Int. Ed., 2019, 58, 5422-5426. (g) K. Li, T. P. Gonçalves, K.-W. Huang and Y. Lu, Angew. Chem. Int. Ed., 2019, 58, 54275431. (h) A. Cerveri, O. N. Faza, C. S. López, S. Grilli, M. Monari and M. Bandini, J. Org. Chem., 2019, 84, 6347-6355. (i) L. Birbaum, L. Gillard, H. Gérard, H. Oulyadi, G. Vincent, X. Moreau, M. De Paolis and I. Chataigner, Chem. - Eur. J., 2019, 25, 13688-13693. (j) J. Ling, D. Mara, B. Roure, M. Laugeois and M. R. Vitale, J. Org. Chem., 2020, 85, 3838-3848.

7 See for instance: (a) T. L. S. Kishbaugh and G. W. Gribble, Tetrahedron Lett., 2001, 42, 4783-4785. (b) M. Victoria Gómez, A. I. Aranda, A. Moreno, F. P. Cossío, A. de Cózar, Á Díaz-Ortiz, A. de la Hoz and P. Prieto, Tetrahedron, 2009, 65, 5328-5336. (c) M. Andreini, M. De Paolis and I. Chataigner, Catal. Commun., 2015, 63, 15-20. (d) Y. Li, F. Tur, R. P. Nielsen, H. Jiang, F. Jensen and K. A. Jørgensen, Angew. Chem. Int. Ed., 2016, 55, 1020-1024. (e) M. Andreini, F. Chapellas, S. Diab, K. Pasturaud, S. R. Piettre, J. Legros and I. Chataigner, Org. Biomol. Chem., 2016, 14, 2833-2839. (f) D.-F. Yue, J.-Q. Zhao, X.-Z. Chen, Y. Zhou, X.-M. Zhang, X.-Y. Xu and W.-C. Yuan, Org. Lett., 2017, 19, 4508-4511. (g) P. V. Santhini, A. Krishnan R, S. A. Babu, B. S. Simethy, G. Das, V. K. Praveen, S. Varughese and J. John, J. Org. Chem., 2017, 82, 10537-10548. (h) S. Diab, L. Noël-Duchesneau, M. Sanselme, Y. Kondo, M. De Paolis and I. Chataigner, Eur. J. Org. Chem., 2018, 2018, 2048-2052. (i) D. Cao, A. Ying, H. Mo, D. Chen, G. Chen, Z. Wang and J. Yang, J. Org. Chem., 2018, 83, 12568-12574. (j) K. Pasturaud, B. Rkein,
M. Sanselme, M. Sebban, S. Lakhdar, M. Durandetti, J. Legros and I. Chataigner, Chem. Commun., 2019, 55, 7494-7497.

8 (a) I. Zenz and H. Mayr, J. Org. Chem., 2011, 76, 9370-9378. (b) D. S. Allgäuer, H. Jangra, H. Asahara, Z. Li, Q. Chen, H. Zipse, A. R. Ofial and H. Mayr, J. Am. Chem. Soc., 2017, 139, 1331813329.

9 M. Beuvin, M. Manneveau, S. Diab, B. Picard, M. Sanselme, S. R. Piettre, J. Legros and I. Chataigner, Tetrahedron Lett., 2018, 59, 4487-4491.

10 The chemoselectivity of the cycloaddition can be questionned since the reactivity of 3-carbonylated indoles/pyrroles in $(4+2)$ reactions involving electron-rich 1,3dienes depends on the nature of both the electronwithdrawing group borne by the arene and the diene. Hence, in the presence of polarized dienes such as Danishefsky diene, an heterocycloaddition is observed on the $\mathrm{C}=\mathrm{O}$ bond of the activating group, being formyl, ketoester or even secondary ketoamide. See: (a) A. Chrétien, I. Chataigner, N. L'Hélia and S. R. Piettre, J. Org. Chem., 2003, 68, 7990-8002. (b) A. Chrétien, I. Chataigner and S. R. Piettre, Tetrahedron, 2005, 61, 79077915. In contrast, the reaction preferably involves the aromatic $\mathrm{C}=\mathrm{C}$ bond when the electron-withdrawing group is a nitro, a tertiary ketoamide or an ester for instance. See ref. 3 and 7

11 The discrepancy between the conversion rate and the isolated yield may be attributed to the large amount of aminated dimer/oligomers/polymers resulting from the selfcondensation of the in-situ generated azomethine ylide, present in a large excess, rendering difficult the isolation of the cycloadduct. No presence of deprotected indole substrate nor cycloadduct was detected in the crude ${ }^{1} \mathrm{H}$ NMR mixture.

12 I. Chataigner, C. Panel, H. Gérard and S. R. Piettre, Chem. Commun., 2007, 3288-3290.

13 3-Cyanoindoles substituted by an aromatic group were prepared from non-protected 5-bromo-3-cyano-1H-indoles, through Suzuki-Miyaura cross coupling reactions. See M. A. Düfert, K. L. Billingsley and S. L. Buchwald, J. Am. Chem. Soc. 2013, 135, 12877-12885 and ESI.

$14 \mathrm{~A}$ reaction time of $2 \mathrm{~h}$ was selected to ensure full conversion for all substrates.

15 (a) D. Webb and T. F. Jamison, Chem Sci 2010, 1, 675-680; (b) J. Yoshida, H. Kim and A. Nagaki, ChemSusChem 2011, 4 331-340; (c) L. Malet-Sanz and F. Susanne, J. Med. Chem. 2012, 55, 4062-4098; (d) J. C. Pastre, D. L. Browne and S. V. Ley, Chem. Soc. Rev. 2013, 42, 8849-8869; (e) S. V. Ley, D. E. Fitzpatrick, R. M. Myers, C. Battilocchio and R. J. Ingham, Angew. Chem. Int. Ed. 2015, 54, 10122-10136; (f) M. B. Plutschack, B. Pieber, K. Gilmore, P. H. Seeberger, Chem. Rev. 2017, 117, 11796-11893; (g) R. Gérardy, N. Emmanuel, T. Toupy, V.-E. Kassin, N. N. Tshibalonza, M. Schmitz and J.-C. M. Monbaliu, Eur. J. Org. Chem. 2018, 2301-2351.

16 (a) H. Usutani, Y. Tomida, A. Nagaki, H. Okamoto, T. Nokami and J. Yoshida, J. Am. Chem. Soc. 2007, 129, 3046-3047; (b) H. Kim, A. Nagaki and J. Yoshida, Nat. Commun. 2011, 2, 264; (c) H. Kim, K.-I. Min, K. Inoue, D. J. Im, D.-P. Kim and J. Yoshida, Science 2016, 352, 691-694; (d) A. Nagaki, D. Ichinari and J. Yoshida, J. Am. Chem. Soc. 2014, 136, 12245-12248; (e) T. Lebleu, J. Maddaluno and J. Legros, Org. Chem. Front. 2015, 2, 324-327; (f) B. Picard, B. Gouilleux, T. Lebleu, J. Maddaluno, I. Chataigner, M. Penhoat, F.-X. Felpin, P. Giraudeau and J. Legros, Angew. Chem. Int. Ed. 2017, 56, 7568-7572; (g) B. Picard, K. Pérez, T. Lebleu, D. Vuluga, F. Burel, D. C. 
Harrowven, I. Chataigner, J. Maddaluno and J. Legros, J. Flow Chem., 2020, 10, 139-143.

17 M. Baumann, I. Baxendale and S. Ley, Synlett 2010, 749-752. 18 See for instance: (a) V. Sharma, P. Kumar and D. Pathak, J. Heterocycl. Chem. 2010, 47, 491-502; (b) E. Stempel, T. Gaich, Acc. Chem. Res. 2016, 49, 2390-2402; (c) P. H. B. França, D. P. Barbosa, D. L. da Silva, Ê. A. N. Ribeiro, A. E. G. Santana, B. V. O. Santos, J. M. Barbosa-Filho, J. S. S. Quintans, R. S. S. Barreto, L. J. Quintans-Júnior, et al., BioMed Res. Int. 2014, 1-12; (d) I. Giménez Sonsona, Synlett 2015, 26, 2325-2326; (e) T. V. Sravanthi and S. L. Manju, Eur. J. Pharm. Sci. 2016, 91, 1-10; (f) N. Netz and T. Opatz, Mar. Drugs 2015, 13, 4814-4914; (g) M. E. Tanner, Nat. Prod. Rep. 2015, 32, 88-101. 